\title{
Immune Status of Children Living in Industrial Developed Regions in the Conditions of Chronic Exposition of Anthropogenic Chemical Factors (by the Example of Benz(a)pyren, Phenol and Mercury)
}

\author{
N.A. Nikonoshina ${ }^{1}$, O.V. Dolgikh ${ }^{1}$ and N.V. Zaitseva ${ }^{1}$ \\ ${ }^{1}$ Federal Scientific Research Center for Medical and Preventive Health Risk Management Technologies, 82, \\ Monastyrskaya str., Perm, 614045, Russia \\ ${ }^{*}$ Corresponding author. Email: nat08.11@yandex.ru
}

\begin{abstract}
Excessive exposure to anthropogenic environmental factors on the territory of chemical production enterprise causes changes in the microelement composition of biological media of the child population characterized by an increased level of blood contamination with benzo(a)pyrene and phenol ( $\mathrm{p}<0.05$ ), as well as an excess mercury concentration in urine in relation to the control group. The immune status of the group under study is characterized by an increase in the level of hapten-specific sensitization to man-made chemical factors in a given territory according to the criterion of $\operatorname{IgG}$ to phenol, IgG to benzo(a)pyrene, IgG to epichlorohydrin and IgG to mercury $(\mathrm{p}<0.05)$. The revealed decrease in the content of $\mathrm{CD}^{+} \mathrm{CD}^{+}$- and $\mathrm{CD}^{+} \mathrm{CD}^{+}$-lymphocytes resulting in the immunoregulatory index of $\mathrm{CD}^{+} / \mathrm{CD} 8^{+}$, as well as inhibition of the phagocytic activity of leukocytes according to the criteria of a decrease in the percentage of phagocytosis, phagocytic number, phagocytic index and absolute phagocytosis indicate the development of immunodeficiency links of innate and acquired immunity among children under study. The established features of immune regulation (overproduction of $\mathrm{IgG}$ to phenol, $\operatorname{IgG}$ to benzo(a)pyrene, $\operatorname{IgG}$ to epichlorohydrin and $\operatorname{IgG}$ to mercury; deficiency of $\mathrm{CD}^{+} \mathrm{CD}^{+}$- and $\mathrm{CD}_{3}^{+} \mathrm{CD}^{+}$-) against the background of increased contamination of biological media with benz(a)pyrene, phenol and mercury characterizes the immune status peculiarities of the child population living under conditions of excessive haptenic load, and are recommended as marker indicators for early diagnosis of health disorders associated with the immune system.
\end{abstract}

Keywords: Immune status, industrial developed regions, anthropogenic chemical factors, child population

\section{INTRODUCTION}

Technogenic pollution of the environment of industrially developed regions is one of the most important environmental problems at the present stage of society's development. At the same time, heavy metals, including mercury and arsenic, are priority pollutants of environmental objects of the territories where chemical industry enterprises are located [1].

Redundant accumulation of highly toxic substances in the human body triggers reactions of environmental maladaptation and, as a result, violations of homeostatic equilibrium. Identified early changes nervous, humoral and immune regulation of physiological processes in the body can later be transformed into pronounced clinical syndromes of environmentally caused diseases [2-4]

Excessive exposure to anthropogenic environmental factors on the territories where chemical industry enterprises are located has a negative impact on the health of the population of the residential areas [5]. At the same time, it is the children's population that is most vulnerable to changes in the quality of the environment due to the imperfection of adaptation and detoxification processes in the growing body of a child, which, under 
conditions of excessive haptenic load, creates an increased risk for early development of ecologically caused pathologies [6-8].

Currently, with the purpose of ensuring environment safety and preserving the health of population, the study of adaptive reactivity when the quality of the environment changes, including the analysis of changes in immune regulation under the influence of antropogenic environmental factors using modern biomedical technologies, is of particular importance [9-11].

The purpose of the work is study of the features of the immune status of child population of an industrially developed region under conditions of chronic exposure to anthropogenic chemical factors (for example, benzo(a)pyrene, phenol and mercury).

\section{MATERIALS AND METHODS}

A clinical and laboratory examination of the child population of an industrially developed region was carried out. In total, 346 children aged 3 to 10 years were examined.

The study group consisted of 283 people living in the conditions of excessive hapten load in the vicinity of former production facility of chemical products the main anthropogenic chemical factors of which are benzo(a)pyrene, mercury and phenol.

The control group consisted of 63 people who are not influenced to excessive exposure to these factors.

The groups under study are comparable in terms of ethnicity, gender and age, as well as their social status.

The study was carried out in accordance with the standards set out in the World Medical Association Declaration of Helsinki: Ethical Principles for Medical Research Involving Human Subjects. Parents or other legal representatives of minors signed a voluntary informed consent for the examination of children.

The phenol content in the blood was determined by gas chromatography on Chromatek-Kristall 5000 (Chromatek, Russia); benz(a)pyrene in blood was identified by high performance liquid chromatography Agilent 1200 (Agilent Technologies Inc., USA). The mercury content in urine was determined by inductively coupled plasma mass spectrometry using Agilent 7900cx (Agilent Technologies Inc., USA).

The analysis of the population and subpopulation composition of lymphocytes, including the identification of cellular $\mathrm{CD}^{+} \mathrm{CD}^{+}-$and $\mathrm{CD}^{+}{ }^{+} \mathrm{CD}^{+}$markers, was carried out using modern biomedical technologies by flow cytometry, FACSCalibur (Becton Dickinson, USA) using the CellQuestPrO universal program.

The study of the phagocytic activity of peripheral venous blood leukocytes according to the criteria of percentage of phagocytosis, phagocytic number, phagocytic index and absolute phagocytosis was carried out using formalinized sheep erythrocytes.

The method of allergosorbent test with an enzyme label was used to determine the level of specific sensitization to haptens - IgG to mercury, $\operatorname{IgG}$ to epichlorohydrin, IgG to phenol, IgE to nickel.

The mathematical statistics methods were used for statistical processing of the results of the study using the Statistica 10.0 software package (StatSoft, USA). To assess the level of reliability of the obtained data, the parametric Student's test was used, taking into account normal distribution of variables in the control groups.

In case of deviation from the normal distribution, the nonparametric Mann-Whitney U-test was used to compare the data. The research results are presented as the arithmetic mean $(\mathrm{X})$ and its standard error $\left(\mathrm{S}_{\mathrm{X}}\right)$ of the studied indicators. Differences between groups were considered statistically significant at $\mathrm{p}<0.05$.

\section{RESULTS}

The results of preliminary ecological assessment of the quality of objects of the habitat of the group under study, namely the territory of location of the chemical production enterprise, indicate that the average annual concentrations of pollutants in the air systematically exceed the hygienic standards for the content of suspended particles, ben(a)pyrene, formaldehyde, lead and ammonia at the level of up to 1.2 threshold level value continuous exposure.

One-time excess of the level of atmospheric air pollution in terms of hydrogen sulfide was recorded and amounted to almost 5.63 MPC one-time; nitrogen dioxide - 4.1 MPC one-time; sulfur dioxide - 2.66 MPC one-time; nitric oxide - 2 MPC one-time.

In addition, the constant presence of heavy metals, i.e., manganese, copper, nickel at the level of up to 0.04 threshold level value continuous exposure was found in the atmospheric air.

In the soil, there is an excess of hygienic standards for the content of manganese, lead and zinc at the level of 1.7-2.7 MPC.

In the snow cover, the content of soluble mercury compounds on average does not exceed the background level, however, single maximum values recorded in the immediate vicinity of the territory of former chemical enterprise reach $3.2 \mathrm{~F}$ relative to the background level. $[11,12]$.

As a result of chemical and analytical study of the biological media of children living in the vicinity of the area of former chemical enterprise, changes in the microelement composition of the biological media of the group under study were established (Table 1), characterized by a 
significantly increased level of blood contamination with benzo(a)pyrene and phenol, as well as an increased level of mercury in urine in relation to the control group ( $\mathrm{p}<0.05$ ). In addition, the content of benzo(a)pyrene in blood and mercury in urine significantly exceeds the established reference levels for these indicators ( $\mathrm{p}<0.05)$.

Humoral immune status of children living under conditions of excessive haptenic load is characterized by an increase in the level of specific sensitization to technogenic environmental factors according to the criterion of IgG to phenol, IgG to benzo(a)pyrene, IgG to epichlorohydrin and $\mathrm{IgG}$ to mercury relative to the control group ( $p<0,05)$. It was also found that the level of IgG to phenol, IgG to epichlorohydrin and $\mathrm{IgG}$ to mercury significantly exceeds the reference level $(\mathrm{p}<0.05)$ (Table 2).

Table 1. Microelement composition features of biological media of child population, living in conditions of excessive exposure to anthropogenic chemical factors

\begin{tabular}{|c|c|c|c|}
\hline Indicator & Reference level & Study Group (n=283) & Control Group (n=63) \\
\hline Benz(a)pyrene [blood], $\mu \mathrm{g} /$ cubic dm & 0 & $0.011000 \pm 0.001844^{*} / * \star$ & $0.005333 \pm 0.001646$ \\
\hline Phenol [blood], $\mu \mathrm{g} /$ cubic $\mathrm{cm}$ & $0.01-0.0369$ & $0.038218 \pm 0.005661^{*}$ & $0.017771 \pm 0.003719$ \\
\hline Mercury [urine], $\mu \mathrm{g} /$ cubic $\mathrm{cm}$ & 0 & $0.00027 \pm 0.00005^{\star} / * *$ & $0.00017 \pm 0.00004$ \\
\hline
\end{tabular}

Table 2. Humoral immune status features of child population living in conditions of excessive exposure to anthropogenic chemical factors

\begin{tabular}{|l|l|l|l|}
\hline Indicator & $\begin{array}{l}\text { Reference } \\
\text { level }\end{array}$ & $\begin{array}{l}\text { Study Group } \\
(\mathrm{n}=283)\end{array}$ & $\begin{array}{l}\text { Control } \\
\text { Group }(\mathrm{n}=63)\end{array}$ \\
\hline $\begin{array}{l}\text { IgG to mercury, } \\
\text { c.u. }\end{array}$ & $0-0.1$ & $0.162 \pm 0.017^{\star / * *}$ & $0.064 \pm 0.012$ \\
\hline $\begin{array}{l}\text { IgG to } \\
\text { epichlorohydrin, } \\
\text { units/ml }\end{array}$ & $0-0.1$ & $0.199 \pm 0.02^{*}$ & $0.077 \pm 0.01$ \\
\hline $\begin{array}{l}\text { IgG to benzo (a) } \\
\text { pyrene, c.u. }\end{array}$ & $0-0.3$ & $0.209 \pm 0.015^{\star / * *}$ & $0.073 \pm 0.010$ \\
\hline $\begin{array}{l}\text { Note: } \\
*-\text { differences between groups are statistically significant }(\mathrm{p}<0.05) \\
*-\text { differences with reference level are statistically significant }(\mathrm{p}<0.05)\end{array}$
\end{tabular}

Changes in the immune regulation of the child population of the territory the territory of location of the chemical production enterprise indicate the signs of suppression of cellular link of the immune response (Table 3).

The results of phenotyping of populations and subpopulations of lymphocytes in the examined group indicate signs of suppression of the adaptive cellular immune response, which is manifested in a deficiency of $\mathrm{CD} 3+\mathrm{CD} 4+-$ and $\mathrm{CD} 3+\mathrm{CD} 8+$ lymphocytes relative to the control group within the physiological standard $(\mathrm{p}<0.05)$.

The decrease in the number of T-helpers (CD3+CD4+) and cytotoxic lymphocytes (CD3+CD8+) is a decrease in the calculated immunoregulatory index $\mathrm{CD}^{+} / \mathrm{CD}^{+}$in relation to the control group $(\mathrm{p}<0.05)$, which also indicates the development of adaptive cellular immunodeficiency in the group under study.

Table 3. Cellular immune status features of child population living in conditions of excessive exposure to anthropogenic chemical factors

\begin{tabular}{|c|c|c|c|}
\hline Indicator & $\begin{array}{l}\text { Reference } \\
\text { level }\end{array}$ & $\begin{array}{l}\text { Study Group } \\
(\mathrm{n}=283)\end{array}$ & $\begin{array}{l}\text { Control Group } \\
(n=63)\end{array}$ \\
\hline $\begin{array}{l}\text { CD3 }{ }^{+} \mathrm{CD}^{+}{ }^{+}- \\
\text {lymphocytes, } \\
\text { abs., } 10^{9} / \mathrm{l}\end{array}$ & $0.41-1.59$ & $0.912 \pm 0.064^{*}$ & $1.341 \pm 0.077$ \\
\hline $\begin{array}{l}\text { CD3 }{ }^{+} \mathrm{CD}^{+}{ }^{+}- \\
\text {lymphocytes, } \\
\text { rel., \% }\end{array}$ & $31-60$ & $36.495 \pm 1.343^{*}$ & $47.357 \pm 1.806$ \\
\hline $\begin{array}{l}\text { CD3 }{ }^{+} \mathrm{CD}^{+}{ }^{+} \\
\text {lymphocytes, } \\
\text { abs., } 10^{9} / \mathrm{l}\end{array}$ & $0.19-1.14$ & $0.957 \pm 0.074^{*}$ & $1.173 \pm 0.086$ \\
\hline $\begin{array}{l}\mathrm{CD}^{+}{ }^{+} \mathrm{CD} 8^{+}- \\
\text {lymphocytes, } \\
\text { rel., \% }\end{array}$ & $13-41$ & $37,876 \pm 1,782^{*}$ & $40.558 \pm 1.762$ \\
\hline $\mathrm{CD}^{+} / \mathrm{CD}^{+}$, c.u. & $0.8-4.2$ & $1.012 \pm 0.073^{*}$ & $2.093 \pm 0.933$ \\
\hline
\end{tabular}




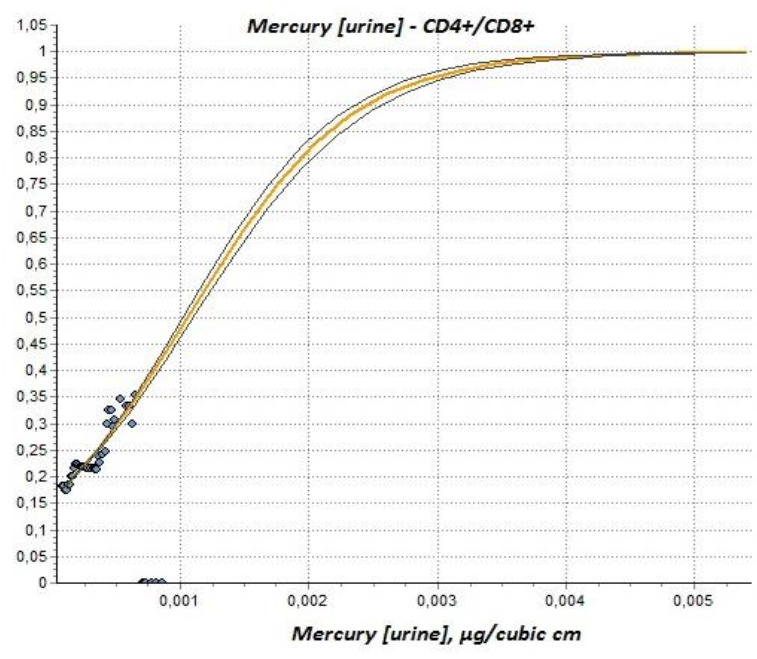

Figure 1. Probability of CD4+/CD8+ decrease depending on increasing biomedia contamination with mercury

There is established dependence of a decrease in the immunoregulatory index CD4+/CD8+ with an increase in the level of mercury bio-mediums in children living in conditions of excessive technogenic exposure $\left(\mathrm{p}<0.05, \mathrm{R}^{2}=0.799\right)$ (Figure 1).

At the same time, the established decrease in the phagocytic activity of leukocytes according to the criterion of the percentage of phagocytosis, phagocytic number, phagocytic index and absolute phagocytosis indicates the inhibition of the cellular link of the innate immune response in children with excessive contamination of biological media with benz(a)pyren, phenol and mercury $(\mathrm{p}<0.05)$ (Table 4).

Table 4. Features of leukocyte phagocytic activity of child population living in conditions of excessive exposure to anthropogenic chemical factors

\begin{tabular}{|l|l|l|l|}
\hline Indicator & $\begin{array}{l}\text { Reference } \\
\text { level }\end{array}$ & $\begin{array}{l}\text { Study Group } \\
(\mathrm{n}=283)\end{array}$ & $\begin{array}{l}\text { Control } \\
\text { Group }(\mathrm{n}=63)\end{array}$ \\
\hline $\begin{array}{l}\text { Absolute } \\
\text { phagocytosis, } \\
10 \% \text { cubic dm }\end{array}$ & $0.964-2.988$ & $1.157 \pm 0.088^{*}$ & $1.344 \pm 0.133$ \\
\hline $\begin{array}{l}\text { Percentage of } \\
\text { phagocytosis, \% }\end{array}$ & $35-60$ & $0.823 \pm 0.044^{*}$ & $0.976 \pm 0.051$ \\
\hline $\begin{array}{l}\text { Phagocytic } \\
\text { number, c.u. }\end{array}$ & $0.8-1.2$ & $1.783 \pm 0.044^{*}$ & $1.939 \pm 0.053$ \\
$\begin{array}{l}\text { Phagocytic } \\
\text { index, c.u. }\end{array}$ & $1.5-2$ & $0.208 \pm 0.021^{* / * *}$ & $0.151 \pm 0.023$ \\
\hline $\begin{array}{l}\text { Note: } \\
*-\text { differences between groups are statistically significant }(\mathrm{p}<0.05) \\
* *-\text { differences with reference level are statistically significant }(\mathrm{p}<0.05)\end{array}$
\end{tabular}

The dependence of a decrease in the percentage of phagocytosis with an increase in the level of mercury bio-mediums in children living in conditions of excessive technogenic exposure has been established $\left(\mathrm{p}<0.05, \mathrm{R}^{2}=0.884\right)$ (Figure 2).

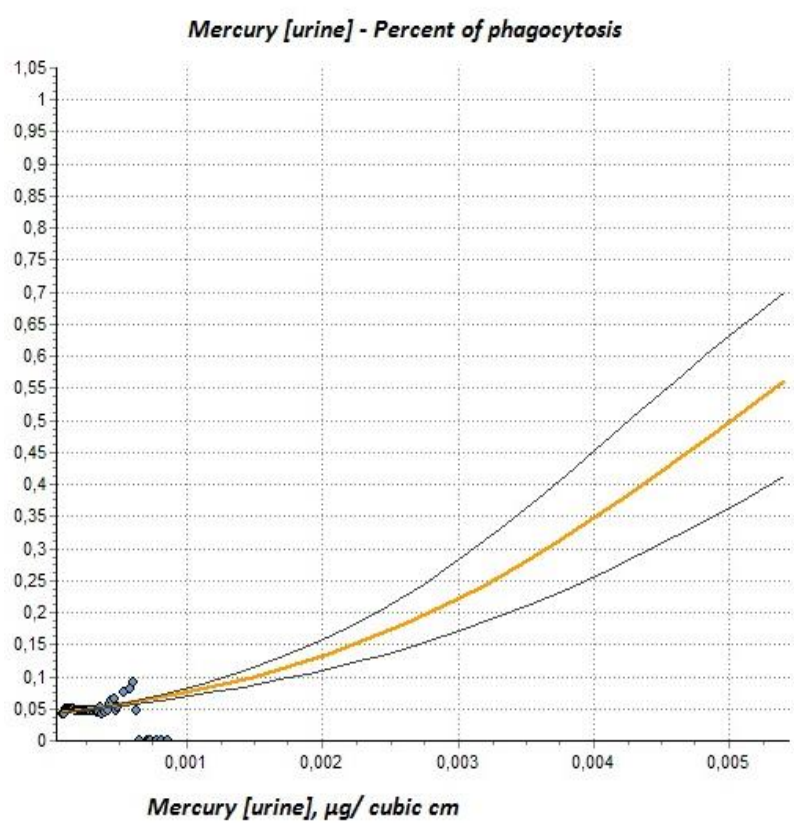

Figure 2. Probability of percent of phagocytosis decrease depending on increasing biomedia contamination with mercury

In this way, the increased exposure of the children's population to technogenic factors of the chemical industry enterprise causes an excessive level of contamination of the biological environment with pollutants and, as a result, multidirectional changes in cellular and humoral immune regulation, including the launch of specific hypersensitization processes and inhibition of the characteristics of the cellular adaptive immune response.

\section{CONCLUSION}

Thus, an excessive exposure to anthropogenic environmental factors on the territory of former production of chemical products causes changes in the microelement composition of the biological media of the child population, namely, an increase in the level of blood contamination with benzo(a)pyrene and phenol and an excess content of mercury in urine in relation to the control group ( $\mathrm{p}<0.05)$. In the control group, the signs of hypersensitization to technogenic chemical factors of the given territory were found: $\operatorname{IgG}$ to phenol, IgG to benzo(a)pyrene, IgG to epichlorohydrin and IgG to mercury ( $\mathrm{p}<0.05$ ). A decrease in the content of CD3+CD4+- and CD3+CD8+ lymphocytes and, as a result, the immunoregulatory index of $\mathrm{CD}^{+} / \mathrm{CD}^{+}$(p $<0.05)$ was revealed. The signs of inhibition of the phagocytic activity of leukocytes were established according to the criterion of a decrease in the percentage 
of phagocytosis, phagocytic number, phagocytic index and absolute phagocytosis $(p<0.05)$ for the purpose of early identification of health disorders. The revealed changes in the immune regulation of children living in the conditions of excessive exposure to anthropogenic environmental factors (overproduction of IgG to phenol, IgG to benz(a)pyrene, IgG to epichlorohydrin and $\operatorname{IgG}$ to mercury; deficiency of CD3+CD4+- and CD3+CD8+-) form a complex features of the immune status of the group under study and can be used for early identification of health disorders and the development of ecologically conditioned pathologies of the child population living under conditions of excessive exposure to anthropogenic chemical factors.

\section{REFERENCES}

[1] A.P. Vertinsky, Innovat. \& Invest. 1 (2020) 232237.

[2] M. Al-Osman, F. Yang, I. Yaw-Massey, Biomet. 32(4) (2019) 563-573.

[3] J. Yann, J. Galineau, A. Hulin, Environ. Int. 66 (2014) 165-171.

[4] Yu.A. Rakhmanin, R.I. Mikhaylova, Hyg. and Sanit. 93(5) (2014) 5-10.
[5] N.V. Zaitseva, O.Yu. Ustinova, A.I. Aminova, Hygienic aspects of children's health disorders under the influence of chemical factors of the environment, Knizhnyy format, Perm, 2011.

[6] O.V. Dolgikh, N.A. Nikonoshina, M.A. Guselnikov, Bull. of Experim. Biol. and Med. 169(5) (2020) 661-664.

[7] M. Chin-Chan, J. Navarro-Yepes, B. QuintanillaVega, Front. in Cellular Neurosci. 10(9) (2015) 124.

[8] D.R. Boverhof, G. Ladics, B. Luebke, Regul. Toxicol. and Pharmacol. 68(1) (2014) 96-107.

[9] State reports on the condition and protection of environment of the Russian Federation for 2012$2018 . \quad$ Retrieved from: http://www.mnr.gov.ru/docs/gosudarstvennye_dokl ady/

[10] State reports on the condition and protection of environment of the Irkutsk Region for 2010-2019. Ministry of Natural Resources and Environment of the Irkutsk Region. Retrieved from: https://irkobl.ru/sites/ecology/ 